\title{
Barriers in the Implementation of Software Process Improvement Project in Saudi Arabia
}

Fahad H. Alshammari*

College of Computing and Information Technology, Shaqra University, KSA; fahad.h@su.edu.sa

\begin{abstract}
Objectives: To identify the barriers as resistance factors that influence the implementation of Software Process Improvement (SPI) in Saudi software companies. Methods/Analysis: This research has developed a questionnaire on a sample of Saudi companies that have implemented SPI. The questionnaire performed from April to July 2018. Forty companies in Saudi Arabia, which are based on software process improvement, have been identified. 251 of 300 professionals who were working in these software companies responded. Findings: The human factors, tools and technology factors, and budget and estimates factors, are playing a vital role in the success of the SPI project. Application: This research provides a comprehensive overview for senior management, especially in Saudi Arabia, to manage the future projects by applying preventive actions.
\end{abstract}

Keywords: Barriers, Resistance Factors, SPI Implementation, SPI in Saudi Arabia, Software Process Improvement, SPI

\section{Introduction}

Nowadays, there is agrowth in awarenesssurrounded by the Software engineering community to develop distinguished quality product from the processes of superior-quality software development. This process has been commenced by the efforts 1,2 . It can be expressing that quality of the process used to build the quality product $^{3}$. $\operatorname{In}^{4}$ proposed a detailed survey, which shows that the software project may fail on several reasons if it is not handled with an effective management. In addition, it can be successfully handled by effective management. Various researchers who are studying SPI and its practitioners are re-concentrating their works on the software engineering process aspect with this concept.

A number of SPI models such as Software Process Improvement and Capability Determination (SPICE) and Capability Maturity Model (CMM $)^{\underline{5}-\underline{8}}$ have been proposed earlier by various researchers.

Excellent achievements and improvements have been gained by the various organizations by implementing these standards present in ISO 9000 and CMM. One of the examples is, Hughes Aircraft increased its productivity level by 4 to 1 by increasing/changing its process of development based on the CMM maturity. This paved a way for saving millions of dollars for it $\%$. This achievement has motivated various software organizations in the process of further application and its establishment in SPI initiatives.

A survey was conducted in Brazil ${ }^{3}$ in order to identify the various resistance factors which influence the adaptation of animprovement projects in software process. From 18 companies, a set of 36 essential questions were collected and further analysed. The main resistance factors, which wereconsidered as sensible for the implementation of SPI, were addressed by this research. Similar, research would be useful to apply in any other developing country. It will help to address and verify the different factors as well as to compare even if there exists any difference in the others, especially in the country such as Saudi Arabia. Apparently, this research focuses the factors which were identified from the previous works done.

$\mathrm{In}^{3}$ surveyed 29 software companies, which have already been applied and engaged with different SPI projects for more than two years. It is a continuation of

${ }^{*}$ Author for correspondence 
the previous survey of a total of 29 companies which have been done in the year 2007. In this research, an increase in the sum of $11^{3}$ to a total of 40 companies in this research, in order to obtain a better outcome from the extra added 11 companies. A set of 4 to 8 questions were framed and distributed to each company with the aim of getting broad views on each and every SPI project. The questions described above wasmainly given to various professionals who are working with software who were directly involved in the various SPI projects.

The following are the findings present in this study divided into six sections. Sectionone depicts the introduction to thevarious advantages of maintaining standards in software process improvement project, and provides an elaborated overview of the various models in software process improvement which are used by various companies which are based on software in Saudi Arabia. Section twogives a set of barriers with respect to the various resistance factors in the adoption of the SPI in the software based companies and proposed methodology is shown in section three. Sectionfourshowsand discussesthe detailed results and analysis of the result obtained from this survey, and discusses the resistance-factors ranking based on the results. The conclusion of this research is provided in section five.

The substantial software development process is a large and tedious process. This involves many project managers, programmers, and software process group. Since these processes are quite complicated to define, and are not easy to interpret, SPI appears to be more efficient to overcome the various hurdles present in a process. It is also used to remove the difficulties more effectively. When the quality process specifies a set of rules, and then it should maintain the quality consistent with those proposed rules. It is the main requirement for a quality or disciplined process. In order to maintain a process to be more effective, the people who were working on its hold know well about it. Therefore, they must be well trained on it. Hence, to produce or maintain a quality in a process, initially, the process has to be defined and further trained to make it mature and this process improves rapidly and periodically ${ }^{9-12}$.

\subsection{Software Process}

The software process isa set of partially ordered steps with process related products, human as well as computerised resources, structures of organization and its various constraints which are proposed to generate and maintain the quality of requested products of software" 10 . In order to improve the software quality, the software standards and models become more significant and considerable in the software industry through the software process management. In recent past, involving of different companies is done according to the earliest models or standards such as CMMI, CMM, SIX Sigma, or ISO 9000.

Modelssuch as CMM, People CMM, CMMI, or DMM usually present great improvements for organizations, which are using it. In ${ }^{11}$ found that an increase in Cost Performance Index (CPI) of approximately 0.95 compared to its previous CPI of 0.38 was achieved by the SPI initiative in BL Informatics. $\operatorname{In}^{12}$ found that there is an improvement in estimation in its schedule and improvements in high-quality. A group of software engineering of three different companies such as Advanced Information Services, Motorola and Union Switch were used SPI model, which is Personal Software Process (PSP) to develop their processes. Application Management Services in IBM Australia attained an improved in onbudget delivery from $90 \%$ to nearly $100 \%$, since it is moved from maturity level 3 of software CMM to maturity level 5 of CMMI. The cost of poor quality is reduced in the Siemens Information Systems Ltd from $45 \%$ to less than $30 \%$ during three yearssince it adopted thematurity level 5 software CMM towards the maturity level 5 of CMMI.

\section{Barriers in an Implementation of Software Process Improvement}

Some companies that are using the SPI based projects reported various problems and difficulties during an implementation process. There exist several factors for influencing, and effective implementation of SPI projects. $\mathrm{In}^{\frac{13}{3}}$ proposed some of the resistance factors which an organization who implements the SPI can apply. $\operatorname{In}^{14}$ focussed on various problems overcome in most of the organizations which implemented SPI. This includes goals which are fluctuating in nature, nullifiedstatus of visualized project in SPI, poorly managed information, distribution of role in an unclear manner and hardly transferred technology. Moreover, in $\frac{15}{5}$ proposed that maintaining effectiveness in communication while developing a software project environment among the developers, users who are using it and project managers 
are the variousfactor for deciding and to minimize the failure of project.

Based on the above defined problems, in ${ }^{16}$ proposed a research finding from the work making as a base ${ }^{3}$. In that research, it classified the resistance factors into two main categories: the Organizational factors and the Project factors.

\subsection{Organizational Factors}

Effectively coordinating different teams which are present in larger or medium organizations hence their practices don't grow out, and it will not affect one another is the man role of a Software processes ${ }^{17}$. The same idea is also proposed by the following researchers. $\operatorname{In}^{18-\underline{23}}$ according to their research, organisational factors can be classified in tofive categories namely 1 . Human 2. Political 3. Cultural 4. Goals and 5. Change management. Therefore, description is illustrated in Table 1.

\subsection{Project Factor}

$\operatorname{In}^{24}$ proposed and others $2, \underline{25}-\underline{29}$, the factors are further classifying into four different categorized under project factors such as 1 . Budget and estimates, 2 . Documentation, 3. Quality, and 4. Tools and technologies. Therefore, description is illustrating (Table 2).

\section{Research Methodology}

\subsection{Sample of the Study}

This research has developed a questionnaire on a sample of Saudi companies that have implemented Software Process Improvement SPI. The questionnaire performed from April $2^{\text {nd }}$ to July $5^{\text {th }}, 2018.40$ companies that are presently using the project, which are based on SPI have been identified around Saudi Arabia. 251 of professionals who were working in these software companies responded.

\subsection{Measures}

The questionnaire of this research is based on questions, which have been previously performed in ${ }^{3}$. This research focuses on identifying the barriers in the implementation of SPI Project in Saudi Arabia. The questionnaire was distributed to several of Saudi software companies, which is using SPI. The five-point Likert scale was used for the measurement of all variables ( $1=$ "strongly disagree" to $5=$ "strongly agree").

\subsection{Data Collection}

The final questionnaire and a cover letter including all necessary clarifications, was sent to the IT managers, projects managers, software process group, and programmers of the companies of the sample. They have selected the answers according to their experience and expertise. Questionnaires were sent only after telephonic contact with them, and then sent via email. 300 questionnaires were distributed on 40 companies that agreed to participate in the survey. 251 of 300 practitioners have replied (83.6\%).

\subsection{Reliability and Validity}

The questionnaire was tested for its content and construct validity. The control for the content validity was conducted prior to the beginning of the survey and included consultation with academics of the field, consultation with experienced practitioners, and pilot testing.

\section{Research Results and Analyses}

\subsection{Population Vital Statistics}

The respondents and companies, which are participating in the survey, areshown in this section. The information is addressedin the first section ofquestions. The engineers working in software-based companies are provided with questionnaires that includethe role of respondentsin acompany, their education level, and their academic majors, duration of working in software development, the time taken in working in SPI project and their experience in SPI. Table 3 shows practitioners according to their roles in an organization. Figure 1 provides the years of involvement of developers in the software development process. Figure 2 shows the years of involvement of developers in the SPI project development. The peoples who are working in this software development processwere also enquiredabout their experience in the SPI using predefined reviewing process. This process starts from bottom to top strategy, which is showing in Figure 3. The data in Figure 3 shows those 70 peoples working in the software development process made them to have their experience as average and 47 people below average. While, 120 rated themselves as having a high experience, and the remaining 14 respondents rated themselves as having excellent experience. Generally, the entire data provides the list of peoples who are having a good and sufficient experience and knowledge in SPI. 
Table 1. Organizational factor description

\begin{tabular}{l} 
Category \\
\hline There is no commitment in the all levels of organization (human) \\
to implement SPI, the initiative can be fail or the results cannot \\
be reaching ${ }^{17}$. Experience of management in SPI project affects \\
improvement process. Consultation and training of SPI staffs \\
is one of challenges in the implementation of SPI project. In $\underline{16}$ \\
addressed that organizational barriers (especially the human \\
category) are important contributing factors to the success of SPI \\
initiatives $\frac{15}{5}$. In $\frac{18}{}$ affirmed the importance of organizational factors \\
affect the personnel motivating projects, and Consequently affect \\
the success of SPI projects.
\end{tabular}

Human

Political

Goals

Change
Management
In $\frac{19}{}$ demonstrated the importance of political factor in the building and creation for a department to SQA. Quality policies for SPI adoption the organizational goals and objectives related to the quality.

$\mathrm{In}^{20}$ proved that in order to ensure success in a cultural change, should be decided who can build, deploy, and drive. However, every cultural change requires excellent cooperation.

In ${ }^{24}$ demonstrated that should the goals, deadlines, and expected results by the managers be logical, otherwise the effort towards SPI may be unsuccessful. $\mathrm{In}^{21}$ showed that "software development is measured in terms of overall progress in meeting functional and business goals" that ensure how the software process is going well. Meanwhile, Clarke and Osterweil $\underline{22}$ found that software process needs to have indefinitely ongoing processes. Therefore, goals and objectives must be clear especially in the earlier phase.

In ${ }^{25}$, discussed the importance of organization' objectives and interests, and how to process the change management. In ${ }^{24}$ mentioned that the SPI project's team should be used actively facilitate process for changes on the project teams rather than just checking the situation of the ongoing process. $\operatorname{In}^{23}$ mentioned that change management should be taking in the account to ensure the success of SPI projects.

\section{Resistance Factors}

-Absence of organizational commitment in all levels

-Deficit of individual participation and adhesion of all the peoples who are involved in SPI projects.

-Absence of individual professional skill and experiences.

-Shortage of guidance and support by the higher authorities.

-Lack of sufficient instruction.

-Shortage of the establishment of organizational policies.

-Shortage of the implementation of Policy in Quality.

-Insufficiency of expertise in adopting changes in cultural level.

-Insufficiency of stability between software processes improvement project and the organization's planned purposes.

-Lack of focussing on the most urgent needs of an organization.

-Impractical belief of the SPI project.

-Shortage and lack of assessment about the on-going software process.

-Development of a team for the software processes improvement project which is not focused on the technical support.

-Focussing continuously on several improvement areas.
Figure 4 displays the entire models used by the 40 companies for obtaining the standards in a software process. From this figure, it can be identified that ISO 9000 is the framework that is mostly used with $55 \%$, and it is followed by Six Sigma with $22 \%$. It is quite complicated to express the various advantages of ISO in Saudi context. The main reasons are due to the flexibility provided by ISO while selecting the processes which are implemented. The ISO 9000 mainly used in various areas due to the support of Saudi Government. Many of the sectors in government, in Saudi Arabia,are using the ISO as their model for quality management for the process of adopting improvement. The Saudi Arabian government is also encouraging official agencies to accomplish the ISO certification. There is/are no other obvious or specific reasons are there for the adaptation of ISO 9000 when compared to SPI models.

\subsection{Resistance Factors}

The questionnaire part comprises of various sections. Therefore, section two deals with the various resistance factors that are contributing for the purpose of limitation 
Table2. Project Factor Description

\begin{tabular}{|c|c|}
\hline Category & Description \\
\hline & $\begin{array}{l}\text { In }{ }^{24} \text { demonstrated the significance of time and costs in the } \\
\text { process evaluation. In }{ }^{26,27} \text { described that cost is the most } \\
\text { challenging factor to handle in software development. In }{ }^{25} \\
\text { mentioned that the significance of SPI project size barrier } \\
\text { and sufficient budget size for SPI project barriers. }\end{array}$ \\
\hline
\end{tabular}

\section{Resistance Factors}

-Budget at present and which crosses the estimated planned value.

-Lack of understanding by the management at top level at which the improvement in software processes project should be a return for long-term and it should be based on an investment process.

-Shortage of visibility for the activities which are processed at present for improving the software processes of a project.

Documentation is necessary in SPI projects, to provide a proof and a reference. According to $\operatorname{In}^{\frac{16}{6}}$ mentioned that the documentation necessary in the list of barriers associated

\section{Documentation}

Quality

Tools \& Technology to SPI. Documentation includes data measurement, proceedings register, coordination and management of the documentation, data collecting the operational framework forms the relationships and dependencies.

A positive advice from experts will lead to positive improvements for software quality. $\operatorname{In}^{28}$ "the increasing cost and complexity of software development is leading software organizations in the industry to search for new ways through process methodology and tools for improving the quality of the software they develop and deliver".

$\mathrm{In}^{29}$ mentioned that complexity of SPI tools and technologies need to have high interest in SPI projects. Therefore, it has high effect on SPI positively or negatively.

\section{-Increased works in documentation.}

-Shortage of documentation works and its infrastructure.

-Shortage of flexibility in the usage of various documents in projects which are of different types and of different sizes.

-Involvement of management from top level is lacking to maintain the relationship between the teams of the complete project and the quality assurance group.

-Shortage of treatment in order to guarantee the overall conformation of process in the instance of weather hiring and/or dismissal of any professionally skilled peoples.

-Change of complete Automatized and well-defined processes

-Training on the tools for support and technologies which are defined as used for supporting is missing.

-Lack and Absence of planning regarding the implementation of the overall period.
SOFTWARE DEVELOPEMENT YEARS

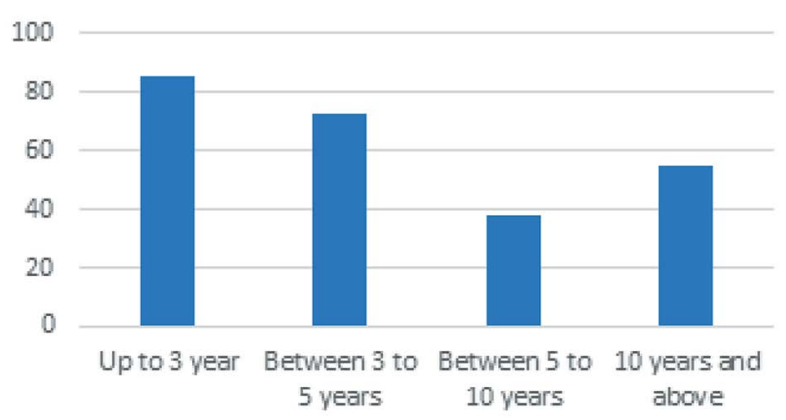

Figure 1. Number of respondents according to years of involvement in software development area.

\section{YEARS IN SPI INVOLVEMENT}

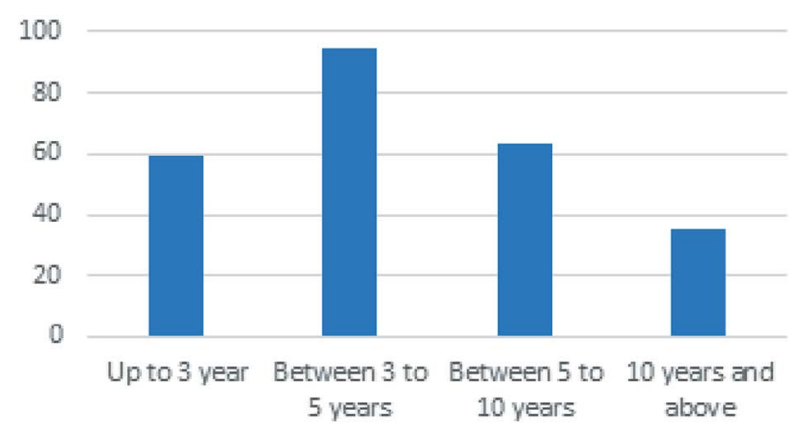

Figure 2. Period of time working in software process improvement project. 
or false step in the implementation of the SPI method. The questions are based on the scale of one to five, from the minimumeffect to the maximumeffectivefactor. Therefore, the practitioners can rate the level of effect from level one (strongly disagree)to five (strongly agree).

\subsubsection{Organizational Resistance Factors Effect}

In order to calculate the factor's effect, this research has used a formula that has been used which is as following:

$$
T\left(f_{n}\right)=\sum R\left(f_{n}\right) \cdot W\left(f_{n}\right)
$$

Where, $T\left(f_{n}\right)$ is the sum of effect level score used in factor $(f)$. It is a total of the overall score given by the user multiplied by score of weightage based on the effect level. $R\left(f_{n}\right)$ is rated by the practitioner in the questionnaire.

\section{EXPERIEN CE IN SPI}

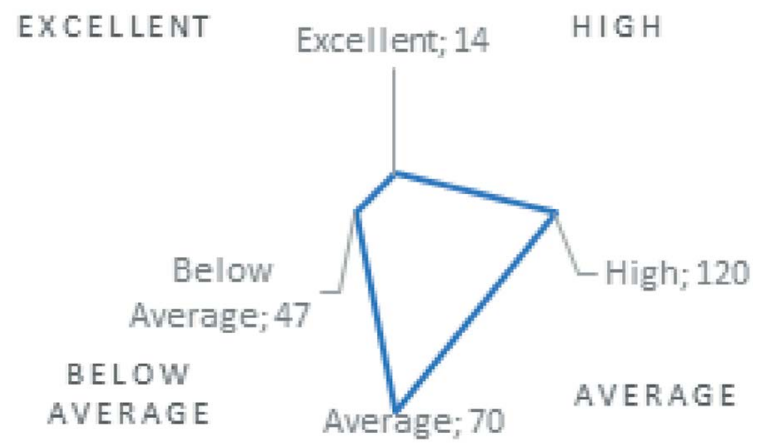

Figure 3. Experience in software process improvement.

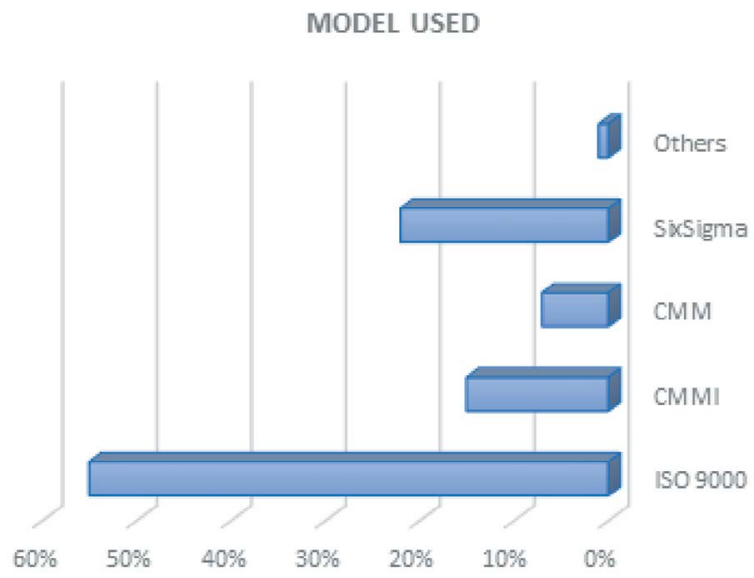

Figure 4. SPI Models.
$W(f n)$ is the weightage score obtained to the factor $(f)$ based on the effect level as shown in Table 4. Fn is the factor number in the questionnaire.

Table 5 shows the total result of effect level for organizational resistance factors, as shown below:

\section{Legend:}

F01 Absence of organizational commitment in all levels F02 Deficit of individual participation and adhesion of all the peoples who are involved in SPI projects

F03 Absence of individual professional skill and experiences.

F04 Shortage of guidance and support by the higher authorities

F05 Lack of sufficientinstruction

F06 Shortage of the establishment of organizational policies.

F07 Shortage of the implementation of Policy in Quality F08 Insufficiency of expertise in adoptingchanges in cultural level.

F09 Insufficiency of stability between software processes improvement project and the organization's planned purposes.

Table 3. Number of respondents according their roles in their organization

\begin{tabular}{ll}
\hline Roles & Numbers \\
\hline Person from Business & 23 \\
Managerial persons of Project or Quality & 19 \\
Consultants from Information Technology & 18 \\
Engineers or Developers of Software & 91 \\
Admins of Systems & 6 \\
Analysists of Systems & 55 \\
Designers & 14 \\
Other peoples & 25 \\
\hline
\end{tabular}

Table 4. Value of effect level and weightage score

\begin{tabular}{ll}
\hline Effect Level, $R$ & Weightage Score, $W$ \\
\hline 1 & 1 \\
2 & 2 \\
3 & 3 \\
4 & 4 \\
5 & 5 \\
\hline
\end{tabular}


F10 Lack of focussing on the most urgent needs of an organization.

F11 Impracticalbeliefof the SPI project.

F12 Shortage and lack of assessment about theon-going software process.

F13 Development of a team for the software processes improvement project which is not focused on the technical support.

F14 focussing continuously on several improvement areas.

The results obtained in Table 5and then shown in a graphical representation, whichare presented. According to Table 5, it isobvious that factor number two (F2), which is "Deficit of individual participation and adhesion of all the peoples who are involved in SPI projects " has the highest effect on the organizational resistance factors. Therefore, it reflects the lack of participation and adhesion in the Saudi's software companies, and this research attributes the reason to few specialists who are responsible and busy with other administrative works inside or outside a company. The second of top five factors is factor number twelve (F12), which is "Shortage and lack of assessment about the on-going software process".It is clear that the lack of specialists and the connection with the factor number two. Hence, the absence of specialist in SPI generates this result within software organizations

Table 5. Total of effect level for the organizational resistance factors

\begin{tabular}{lllllll}
\hline Factor & \multicolumn{3}{l}{ Effect Level (1-5) } & & Total of Effect \\
Number & $\mathbf{1}$ & $\mathbf{2}$ & $\mathbf{3}$ & $\mathbf{4}$ & $\mathbf{5}$ & Level Score, $T$ \\
\hline F01 & 20 & 41 & 55 & 57 & 78 & 885 \\
F02 & 15 & 25 & 57 & 84 & 70 & 922 \\
F03 & 14 & 35 & 68 & 69 & 65 & 889 \\
F04 & 11 & 49 & 61 & 89 & 41 & 853 \\
F05 & 6 & 22 & 93 & 96 & 34 & 883 \\
F06 & 12 & 55 & 68 & 74 & 42 & 832 \\
F07 & 19 & 74 & 82 & 48 & 28 & 745 \\
F08 & 9 & 29 & 95 & 88 & 30 & 854 \\
F09 & 7 & 10 & 102 & 98 & 34 & 895 \\
F10 & 39 & 55 & 113 & 37 & 7 & 671 \\
F11 & 12 & 37 & 96 & 87 & 19 & 817 \\
F12 & 4 & 16 & 98 & 80 & 53 & 915 \\
F13 & 55 & 97 & 90 & 6 & 3 & 558 \\
F14 & 7 & 22 & 93 & 86 & 43 & 889 \\
\hline
\end{tabular}

in Saudi Arabia. While, the third factorsis factor number nine (F9), which is "Insufficiency of stability between software processes improvement project and the organization's planned purposes", and this illustrates that there is a need for a cooperation and engagement for who responsible or supervisor on SPI and top management specially with planning process and an improvement process. Last top five factors and not lastly, are factor number three (F3) and factor number fourteen (F14) which have the same effect in organizational resistance factors. Therefore, the reason might be that with absence the professionals and experiences produced focussing on some improvement areas and neglect the others, and therefore this result would be one of limitation that facing the software process improvement. Meanwhile, the bottom five factors (lowest ranking) of organizational resistance factors, consecutively, are (F4) which is" Shortage of guidance and support by the higher authorities", therefore it means that there is a slow fix and improvement on guidance shortage. Factor number Six (F6) is following of (F4) which is» Shortage of the establishment of organizational policies", therefore it is clear that there is a tie between them which is rolling around the policies and guidance which should be available in an organization and that is why they are in the lowest ranking. The third of the bottom five factors (lowest ranking) is factor number eleven (F11) which is "Impractical belief of the SPI project" which it means that there is awareness for importance of SPI. Those followed by factors number ten (F10) which is "Lack of focussing on the most urgent needs of an organization" which means that in organization there is focussing for organization's needs. The lowest factor in the list is factor number thirteen (F13), which is "Development of a team for the software processes improvement project which is not focused on the technical support", which means that the development of a team is not a big issue in organizationsbecause may be most of team members have an ability and efficiency specially in works which are not in the technical side.

\subsubsection{Total Effect Level for the Project Resistance Factors}

(Table 6) depicts thesumof effectscore level for every project resistance factor based on the formula shown in Section 5.2.1 
Table 6. Total of effect level for the project resistance factors

\begin{tabular}{lllllll}
\hline Factor & \multicolumn{3}{l}{ Effect Level (1-5) } & & Total of Effect \\
Number & $\mathbf{1}$ & $\mathbf{2}$ & $\mathbf{3}$ & $\mathbf{4}$ & $\mathbf{5}$ & Level Score, $T$ \\
\hline F15 & 26 & 30 & 80 & 55 & 60 & 846 \\
F16 & 11 & 9 & 53 & 82 & 96 & 996 \\
F17 & 54 & 68 & 44 & 39 & 46 & 708 \\
F18 & 62 & 73 & 53 & 41 & 22 & 641 \\
F19 & 31 & 54 & 81 & 56 & 29 & 751 \\
F20 & 77 & 58 & 71 & 27 & 18 & 604 \\
F21 & 12 & 11 & 52 & 79 & 97 & 991 \\
F22 & 53 & 61 & 69 & 39 & 29 & 683 \\
F23 & 27 & 29 & 82 & 52 & 61 & 844 \\
F24 & 17 & 33 & 91 & 39 & 71 & 867 \\
F25 & 19 & 38 & 91 & 70 & 33 & 813 \\
\hline
\end{tabular}

\section{Legend:}

F15 Budget at present and which crosses the estimated planned value.

F16 Lack of understanding by the management at top level at which the improvement in software processes project should be a return for long-term and it should be based on an investment process.

F17 Shortage of visibility for the activities which are processed at present for the purpose ofimproving the software processes of a project.

F18 Increased works in documentation.

F19 Shortage of documentation works and its infrastructure.

F20 shortage of flexibility in the usage of various documents in projects which are of different types and of different sizes.

F21 involvement of management from top level is lacking to maintain the relationship between the teams of the complete project and the quality assurance group.

F22 Shortage of treatment in order to guarantee the overall conformation of process in the instance of weather hiring and/or dismissal of any professionally skilled peoples.

F23 Change of complete Automat zed and well-defined processes

F24 Training on the tools for support and technologies which are defined as used for supporting is missing.
F25 Lack and Absence of planning regarding the implementation of the overall period.

According to Table 6, it is obvious that factor number sixteen (F16), which is "Lack of understanding by the management at top level at which the improvement in the software processes project should be a return for longterm and it should be based on an investment process." has the most effect on the project resistance factors. Therefore, it means that there is a need for senior management to understand the importance of the SPI and the benefit which returns on a company by adopting SPI. The second factor of top five factors is factor number twentyone (F21), which is "involvement of management from top level is lacking to maintain the relationship between the teams of the complete project and the quality assurance group". Therefore, it is obvious that there is a strong tie between the first and second factor! This research attribute the reason to that there is no a real commitment or real support from the top management to SPI. Hence, SPI projects are large-scale, complex, and need to a time for adopting. They require considerable investments in personnel, time and money and affect every aspect of Software Company. While, the third of top five factors is factor number twenty-four (F24), which is "Training on the tools for support and technologies which are defined as used for supporting is missing". With the development of technology, the tools used have improved as well. Meanwhile, there should be training on the tools for the staff of the SPI projects. Hence, this would finally return on investments, income of software companies, and would increase the quality of work with fast delivery. The fourth of top five factors is factor number Fifteen (F15), which interests with budget. Where, one of the limitations in SPI projects is exceeding the budget. Hence, still a need to an expert people who can roughly estimate the cost and this is open research area in software engineering. The last top of five factors is factor number twenty-three (F23), which is "Change of complete automatized and welldefined processes". Software companies look to automate processes that are time- and resource-intensive operationally. Therefore, any change with well-defined processes may lead to errors, and that change can affect accelerating the automated process improvements that are achievable through machines and technology. Meanwhile, the bottom five factors (lowest ranking) of project resistance factors, consecutively, are (F19) which is "Short age 
of documentation works and its infrastructure", which means that the documentation process has not highly effective in the SPI projects in Saudi software companies. The second lowest factor is factor number seventeen (F17) which is "Shortage of visibility for the activities which are processed at present for the purpose of improving the software processes of a project", which means that there is an enough visibility for the activities in Saudi companies. The third lowest ranking factor is factor number twenty-two (F22) which is "Shortage of treatment in order to guarantee the overall conformation of process in the instance of weather hiring and/or dismissal of any professionally skilled peoples". Therefore, it reflects an interest of Saudi companies to employ people has a good skills and that is why it came in the lowest list of resistance project factors in Saudi environment. The last two factors, consecutively, factor number eighteen (F18) which is "Increased works in documentation", followed by (F20) which is "shortage of flexibility in the usage of various documents in projects which are of different types and of different sizes", which means that the documentation process is not a big issue in Saudi companies, and it is noticed that documentation process could be overcome and controlled.

\subsection{Comparison and Inference from the Results}

These results are not same when compared with the results obtained $\mathrm{in}^{3}$, these factors are affected directly by the overall size or workmanship of the organization. From the results obtained, it can be notices that when the organization is larger in size or it has bigger workmanship, the time taken to obtain the adaptation from all the areas of the organization is also more. Moreover, this research attributes the difference with in ${ }^{3}$ to a region and an environment, company interesting, commitment, and market trend. Furthermore, company's maturity is one of the most impacts on SPI. Where, organizational barriers are more associated with high maturity companies than with low maturity companies. Therefore, low maturity companies are closely linked to barriers relating to projects such as quality, tools, and technology. This research noticed that top managements address barriers with goals, culture and politics. Project managers are interested with change management, and budgets. Developers are addressed barriers with documentation, communication, tools and technology. From the obtained responses, it can be noticed that proper and planned planning in software development should be done in order to maintain the project implementation schedule more effectively.

\section{Conclusion and Future Work}

This research thoroughly identified and analysed various important factors for resistance that influences the adoption improvement project of the software process development especially in various companies that are operated in Saudi Arabia. The major top five factors and theleast bottom five factors for the resistance factors which were given in Section 5, basically, they conclude the various factors that are designed for organization. Especially, the human factors, tools and technology, and budget and estimates that are playing a vital role in the barriers of the implementation of software process improvement project in Saudi Arabia.

In addition to this, it has been observed that the participation and working of each and every individual in the organization is more important on order to maintain successful deployment of the SPI projects.

The main disadvantage of this work that is one set of questions and only the instrument survey that is used for gathering all the information. In this scenario, all the gathered information are only limited to the predefined questions. An extensive survey and learning and understanding can be obtained if all the other methods for research are used in a combined manner.

Future work in this research paved the way for increasing the participating number of companies and users in additional to the gathered data for the purpose of obtaining a more wide and accurate scenario of the SPI adoption. Various important barriers are there in the SPI which can be easily solved and taken in to account. Barriers such as comparison of various difficulties that are faced by Saudi software companies of big, medium and small in nature that is starting or ongoing implementing the projects based on SPI.

Finally and definitely, the main aim in this research is to assist Saudi software companies or others to manage the upcoming projects more carefully by using proper planning which can further reduce the barriers that are going to occur during the implementation of SPI projects. 


\section{Acknowledgements}

This research neither could not be, nor achieved without Shaqra University encouragement, and its continued support.

\section{References}

1. Deming WE. Out of the Crisis. Cambridge: MIT Press; 1986. p. 1-524.

2. Juran JM, Gryna FM. Juran's quality control handbook. 4th ed. New York: McGraw-Hill Book Company; 1988. p. $1-1774$.

3. Resistance factors in software processes improvement. Available from: https://www.researchgate.net/ publication/220243346_Resistance_Factors_in_Software_ Processes_Improvement

4. Effective Software Management- Where Do We Falter. Available from: https://www.researchgate.net/ publication/249712612_Effective_Software_Management_ Where_Do_We_Falter

5. International Organization for Standardization (ISO)/ Software Process Improvement and Capability Etermination (SPICE). Available from: http://www.isospice.com/categories/SPICE-Project/

6. Russell C, Cheng H. Bootstrap methods in computer simulation experiments. Winter Simulation Conference; 1995. p. 171-7.

7. Paulk MC. A comparison of ISO 9001 and the capability maturity model for software. Software Capability Maturity Model Project; 1994. p. 1-71.

8. Pittsburgh PA. Capability Maturity Model Integration (CMMI). Carnegie Mellon Software Engineering Institute. Version 1.1; 2001. p. 1-708.

9. Pfleeger SL. Software engineering: Theory and practice. Upper Saddle River, NJ: Prentice Hall; 1998. p. 1-576.

10. LonchampJ. Structured conceptual and terminological framework for software process engineering. 2nd International Conference on the Software Process
Continuous Software Process Improvement; 1993. p. 1-194. https://doi.org/10.1109/SPCON.1993.236823

11. Irigoyen Ferreiro A, Santos G, Cerqueira R, Montoni M, Barreto A, Andrea O, Barreto S, Regina Rocha A. Applying ISO 9001: 2000, MPS.BR and CMMI to achieve software process maturity: BL Informatica's Pathway. International Conference on Software Engineering; 2007. p. 642-651.

12. Ferguson P, Humphrey WS, Khajenoori S, Macke Matvya SA. The personal software process: Three industry cases. IEEE Computer. 1997; 30(5):24-31. https://doi.org/10.1109/2.589907

13. Amescua A, García J, Sánchez-Segura M, MedinaDomínguez F. Software process improvement for practitioners based on knowledge management tools. Proceedings of the 5th WSEAS International Conference on Software Engineering, Parallel and Distributed Systems; 2006. p. 24-9.

14. Sakamoto K, Nakakoji K, Takagi Y, Niihara N. Toward computational support for software process improvement activities.InternationalConferenceonSoftwareEngineering; 1998. p. 22-31. https://doi.org/10.1109/ICSE.1998.671099 PMCid:PMC5921589

15. Arshad NH, Mohamed A, Mat Nor Z. Risk factors in software development projects. Proceedings of the 6th WSEAS International Conference on Software Engineering, Parallel and Distributed Systems; 2007. p. 51-6.

16. BeechamS, TracyH,Austen R.Softwareprocessimprovement problems in twelve software companies: An empirical analysis. Empirical Software Engineering. 2003; 8(1):7-42. https://doi.org/10.1023/A:1021764731148

17. Dyba T. Factors of software process improvement success in small and large organizations: An empirical study in the Scandinavian context. ACM SIGSOFT Software Engineering. 2003; 28(5):148-57. https://doi.org/10.1145/949952.940092

18. Kumlander D. Personnel motivating projects: reasons, implementation and risks. Proceedings of the 6th WSEAS International Conference on Software Engineering, Parallel and Distributed Systems; 2007. p. 30-4. 
19. Wheeler S, Duggins S. Improving software quality. Southeast Regional Conference; 1998. p. 300-39. https://doi.org/10.1145/275295.275375

20. Taylor D, McGraw G. Adopting a software security improvement program. IEEE Security and Privacy. 2005; 3(3):88-91. https://doi.org/10.1109/MSP.2005.60

21. Lazic L, Mastorakis N. Cost effective software test metrics. WSEAS Transactions on Computers. 2008; 7(6):559-619.

22. Clarke LA, Osterweil LJ. Continuous self-evaluation for the self-improvement of software. International workshop on Self-Adaptive Software; 2000. p. 27-39. PMid:10865480

23. Miler J, Górski J. Risk-driven software process improvement- A case study. European Software Process Improvement Conference; 2004. p. 1-7.

24. Weigers Karl E. Software process improvement: Ten traps to avoid. Software Development; 1996. p. 1-9.
25. Statz J, Oxley D, O’Toole P. Identifying and managing risks for software process improvement. Decision Support Systems. 2007; 43(1):269-83.

26. Towards a value-based approach in software engineering. Available from: https:/www. researchgate.net/publication/228993690_Towards_a_ value-based_approach_in_software_engineering

27. Ojala P. Experiences of implementing a value based approach. WSEAS Transactions on Information Science and Applications. 2008; 5(4):385-95.

28. Lazić L, Dakića R. The software testing challenges and methods. 9th WSEAS International Conference on Communications; 2007. p. 497-804.

29. Umarji M, Seaman C. Predicting acceptance of software process improvement. Software Engineering Notes. 2005; 30(4):1-6. https://doi.org/10.1145/1082983.1083121 